\title{
EFEITO DE REGULADORES DE CRESCIMENTO NO POTENCIAL OSMÓTICO DE TOMATEIRO (Lycopersicon esculentum Mill. cv. Angela)*
}

\author{
Paulo R.C. Castro** \\ Maria L.R. Duarte **** \\ Carlos C. Machado $* ;: ;$ \\ Carlos Castro ****; \\ Antonio S. Brito ****
}

\begin{abstract}
RESUMO
A importância do estudo do potencial osmótico das plantas deve-se ao fato deste parâmetro ser considerado o principal componente do potencial hídrico, refletindo o equilíbrio de água na planta. Determinou-se o potencial osmótico foliar do tomateiro (Lycopersicon esculentum Mill. cv. "Angela") através de osmômetro de precisão. As plantas haviam sido tratadas com cloreto de (2-cloroetil) trimetilamônio (CCC) $2000 \mathrm{ppm}$, ácido succínico-2,2-dimetilhidrazida (Alar) $3000 \mathrm{ppm}$ e giberelato de potássio (Gibrel) $100 \mathrm{ppm}$, além do controle. Verificou-se que o Gibrel promoveu uma redução no potencial osmótico; sendo que Alar provocon flutuaçôes no potencial do tomateiro "Angela". O CCC causou maior equilíbrio no potencial osmótico foliar do tomateiro. Observou-se que as follas da cultivar "Angela" mostraram potencial osmótico mais alto pela manhã com relação ao período da tarde.
\end{abstract}

\section{INTRODUÇÃO}

O equilíbrio hídrico das plantas está relacionado com a produtividade agrícola, revestindo-se de importância estudos que tratem de fatores capazes de afetar o potencial hídrico das plantas cultivadas. Sabendo-se que o fluxo de água através do sistema solo-planta ocorre em resposta a um gradiente de potencial hídrico, a variação do potencial osmótico, considerado o principal componente do potencial hídrico da célula durante o ciclo fenológico, deve modificar os gradientes de potencial desenvolvidos no sistema solo-planta, afetando, em conseqüềncia, o balanço interno de água na planta. Este balanço, por sua vez, está direta ou indiretamente relacionado a quase todos os processos fisiológicos que se manifestam nos vegetais.

* Entregue para publicação em 7-12-1977.

** Departamento de Botânica. E.S.A. "Luiz de Queiroz" - USP.

*** Curso de Pós-Graduação da E.S.A. "Luiz de Queiroz" - USP. 
WALTER \& VAN STADEN (1965) determinaram o potencial osmótico e o conteúdo de água em diferentes espécies para estudar o efeito da seca nessas plantas. Observaram que as Restionaceae são hidrolábeis, Leucospermum hidroestáveis e as Protea intermediárias.

FILIPOV (1964) verificou que o potencial osmótico das folhas que se encontravam próximas da periferia da copa das árvores era maior durante a época seca em relação ao períođo de maior disponibilidade hídrica.

CINCOVIC (1966) notou potencial osmótico mais elevado em folhas da periferia da macieira 'Red Delicious' com relação às folhas mais internas. Os valores mostraram-se mínimos pela manhã e máximos à tarde. Observou potencial osmótico de - 7 atm nas folhas internas e - 8 atm nas folhas da periferia.

SOLOMONOVSKII (1972) verificou que tomateiros tratados com cloreto de (2-cloroetil) trimetilamônio (CCC) aumentaram a quantidade total de água livre e combinada; observou ainda redução na transpiração das plantas tratadas com o retardador de crescimento.

SINGH \& YOUNG (1971) observaram que tomateiros tratados com soluções de 0,01 a $0,1 \mathrm{M}$ de CCC mostraram redução na altura, diminuição da área foliar e menor perda de água por transpiração, porém notaram aumento na taxa transpiratória por unidade de área foliar.

CASTRO \& JORGE (1974) observaram que aumentos na concentração de CCC aplicado em feijoeiro corresponderam a reduções na perda de água por unidade de área foliar.

KULL (1971) verificou aumento no armazenamento de carboidratos em plantas tratadas com CCC. A concentração de $500 \mathrm{ppm}$ elevou o conteúdo de açúcares, ređuziu o crescimento e não afetou o nível de lipídeos nas plantas.

MISHRA \& PRADHAN (1972) notaram que a aplicação periódica de ácido succínico-2,2-dimetilhidrazida (Alar) em tomateiros atrasa o murchamento das plantas.

LEE et alii (1974) verificaram que plantas de ervilha tratadas com Alar mostraram aumento na turgidez relativa sob déficit hídrico, mas reduziram a taxa de absorção de água sob condições normais de umidade no solo. O retardador de crescimento não afetou os níveis de açúcares redutores e de amido.

COLE et alii (1971) observaram que o ácido giberélico diminuiu a necessidade de água em alfafa sob diversas condições ambientais.

TAL \& IMBER (1971) consideraram a possibilidade das giberelinas induzirem a abertura estcmática, e consequentemente, a perda de água pelas plantas. 
O objetivo deste trabalho foi determinar o efeito da aplicação de CCC, Alar e Gibrel no potencial osmótico foliar do tomateiro 'Angela'.

\section{MATERIAL E MÉTODOS}

O experimento foi realizado em Piracicaba (SP), tendo-se iniciado com a semeadura do tomateiro (Lycopersicon esculentum Mill. cv. 'Angela') em caixa de madeira contendo solo esterilizado, no interior de casa de vegetação. O transplante foi efetuado 12 dias após a semeadura para vasos de cerâmica com capacidade de 12 litros de solo. Colocaram-se 4 plântulas por vaso, tendo-se efetuado o desbaste de 2 delas 32 dias após a semeadura. Utilizaram-se os tratos culturais normalmente empregados para a cultura.

Além do tratamento controle aplicou-se cloreto de (2-cloroetil) trimetilamônio (CCC) na concentração de 2000 ppm, ácido succínico-2,2-dimetilhidrazida (Alar) $3000 \mathrm{ppm}$ e giberelato de potássio (Gibrel) $100 \mathrm{ppm}$. As aplicações dos reguladores de crescimento foram efetuados 39 dias após a semeadura, por pulverização, até que as folhas fícassem inteiramente molhadas.

O potencial osmótico foliar foi determinado no período de 85 a 90 dias após a semeadura do tomateiro. A determinação do potencial osmótico pode ser realizada através de osmômetros de laboratório com alta precisão (ABELE, 1963) . Na tarde do dia anterior à primeira determinação, as plantas foram irrigadas pela última vez, sendo que durante o período noturno ocorreu a percolação da água gravitacional. Foram coletadas ao acaso, durante 6 dias pela manhã $(8,30 \mathrm{hs})$ e à tarde $(14,30 \mathrm{hs}) 4$ folhas da parte mediana superior e 4 folhas da parte mediana inferior da haste dos tomateiros sob os diferentes tratamentos. Cada amostra de 4 folhas foi colocada em envelope de polietileno que foi em seguida fechado com fita adesiva. O envelope contendo as folhas foi então imerso em nitrogênio líquido por 2 minutos. Deixou-se em seguida à temperatura ambiente $\left(25^{\circ}\right)$ por 10 minutos. As folhas foram então colocadas no interior de um cilindro de aço com $2,5 \mathrm{~cm}$ de diâmetro, entre dois círculcs de papel de filtro Whatman $\mathrm{n}^{\circ}$ 1. Neste cilindro adaptou-se uma base de aço e um êmbolo do mesmo material. Colocando-se sob a base de aço um recipiente de alumínio para coleta do extrato, levou-se o sistema à uma prensa Carver para a retirada do extrato foliar. A prensagem foi realizada por 13 segundos a $10.000 \mathrm{~atm}$. Uma amostragem do extrato obtido no recipiente de alumínio foi colocada em uma cubeta com capacidade de $0,2 \mathrm{ml}$ e levada ao osmômetro de laboratório, Osmette, para determinação do potencial osmótico. A leitura obtida em miliosmolalidade foi convertida em atmosferas a $25^{\circ} \mathrm{C}$, multiplicando-se pelo fator 0,024 . Procedeu-se do mesmo modo para todas as amostras .

Efetuou-se a apresentação gráfica dos valores do potencial osmótico em atmosferas no período de 6 dias, considerando os quatro tratamentos, folhas superiores e inferiores, coletadas pela manhã e à tarde. 
Pela figura 1 pode-se notar que o potencial osmótico é inferior

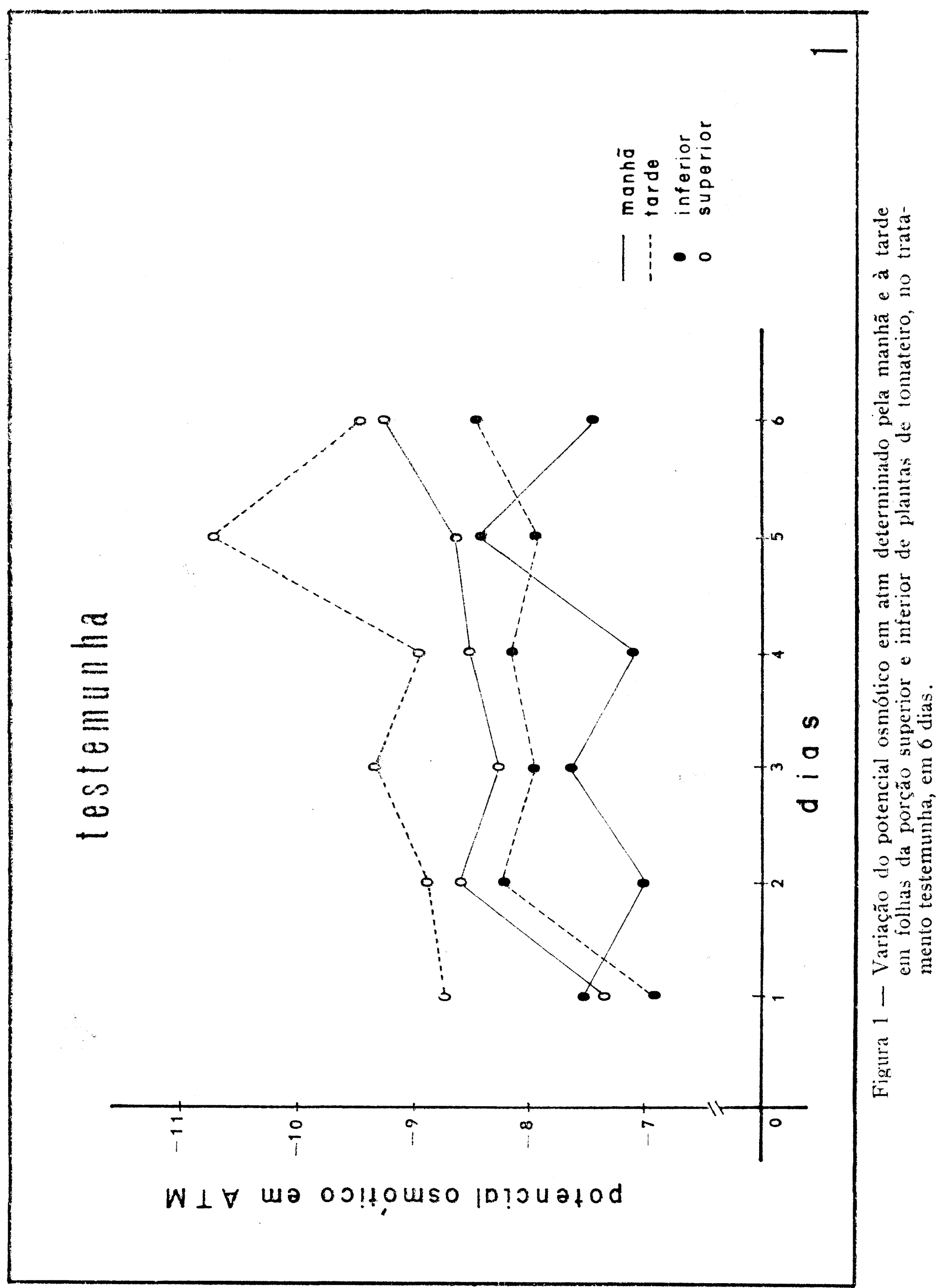




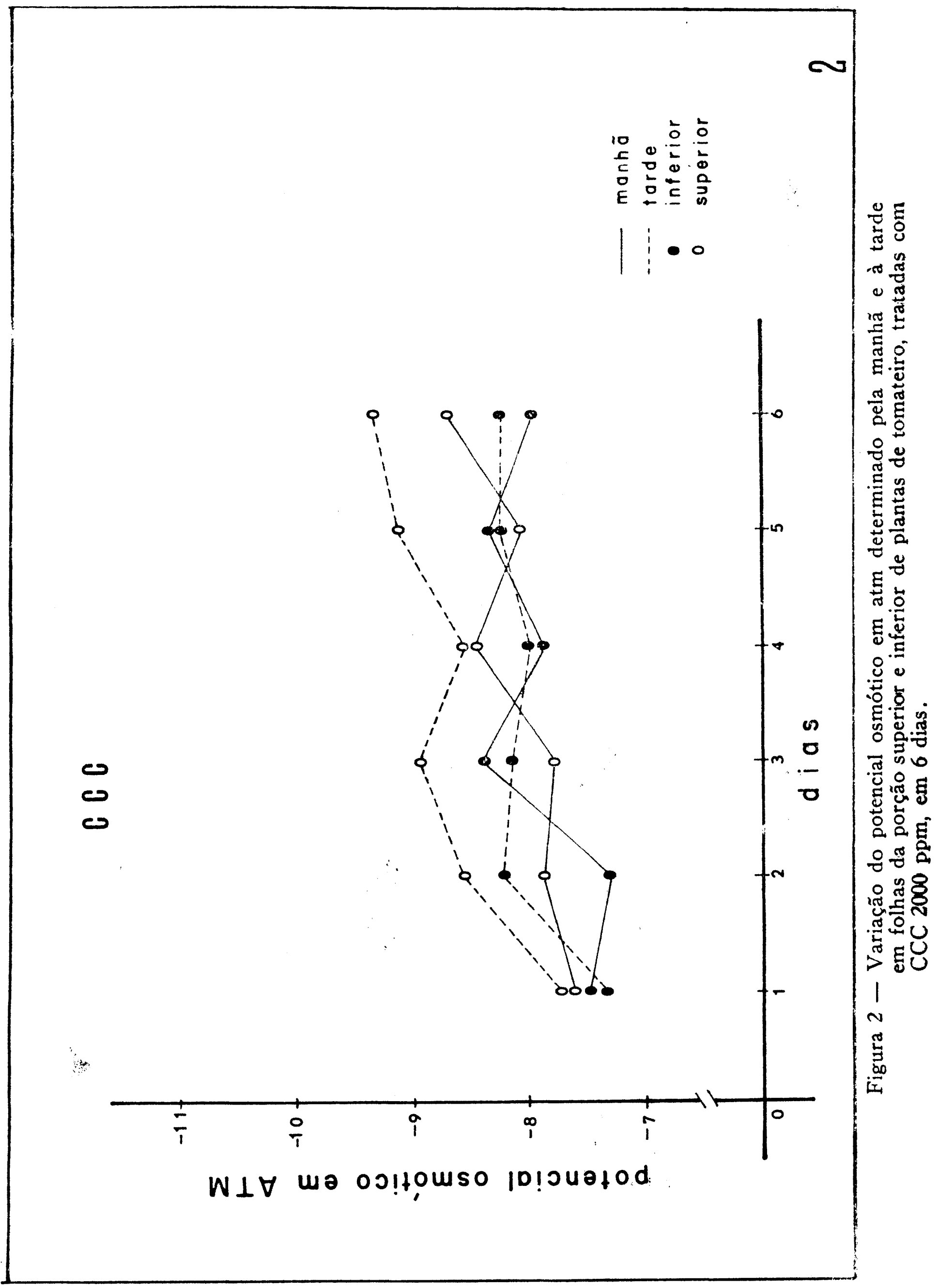




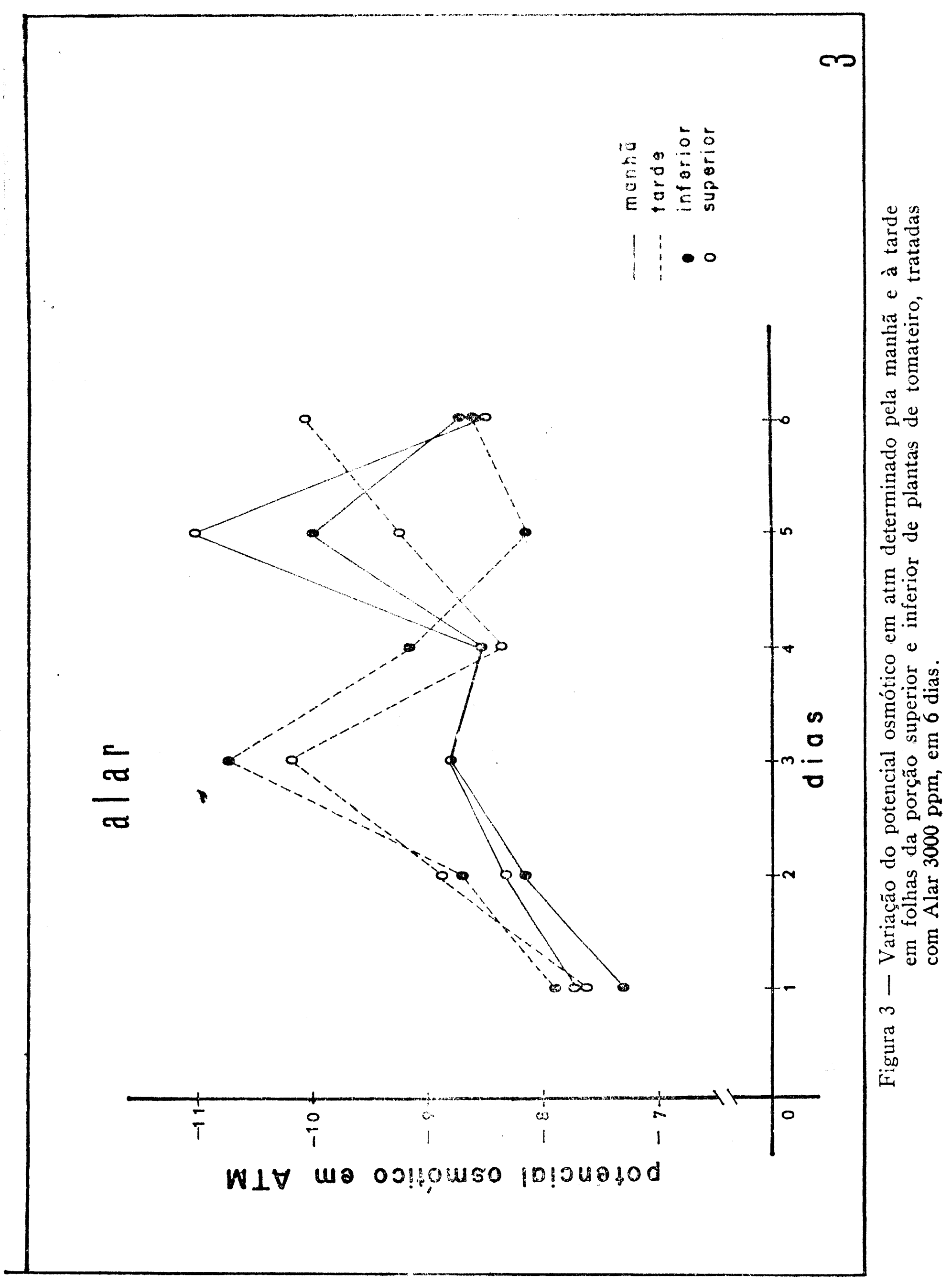




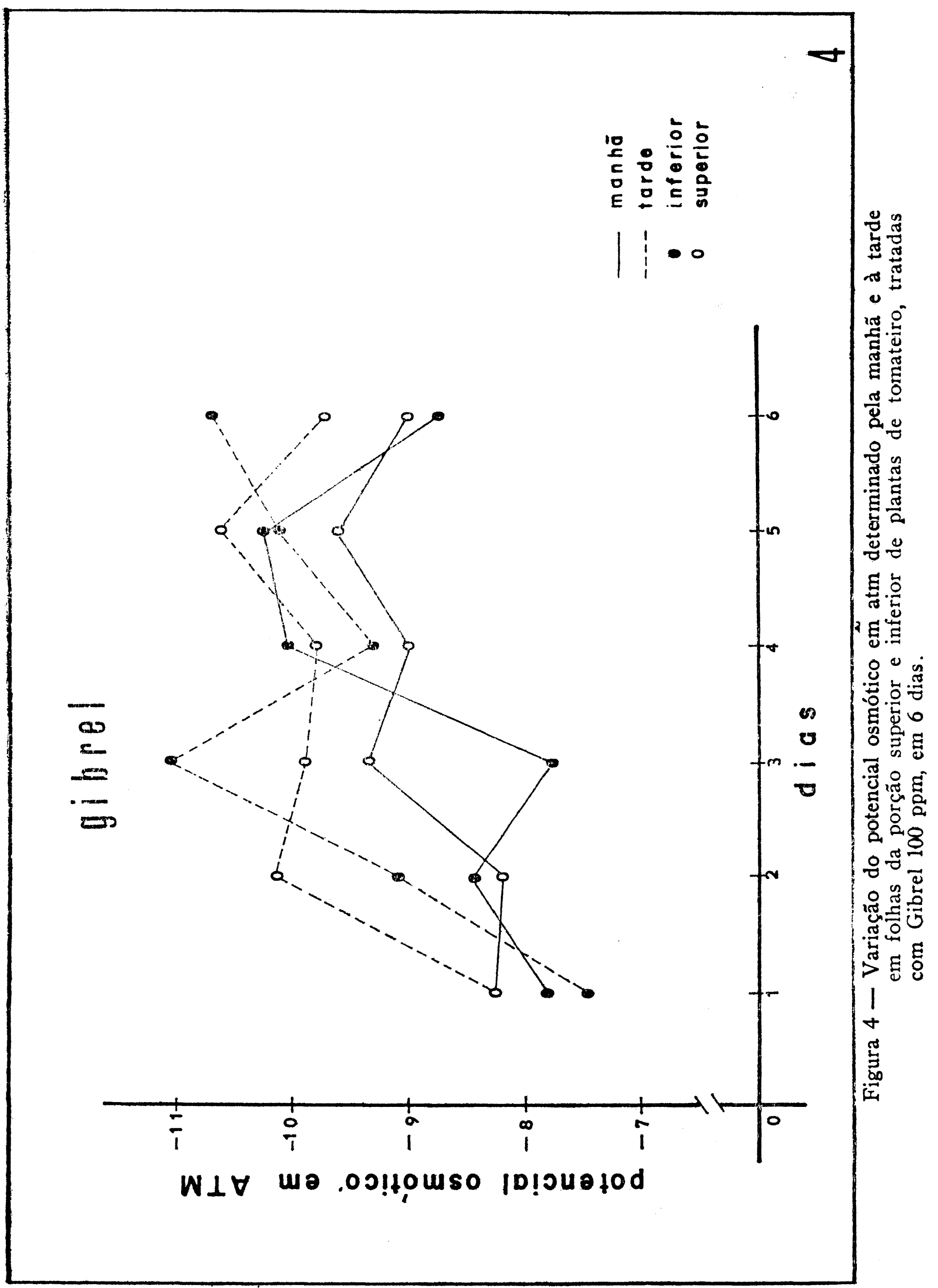




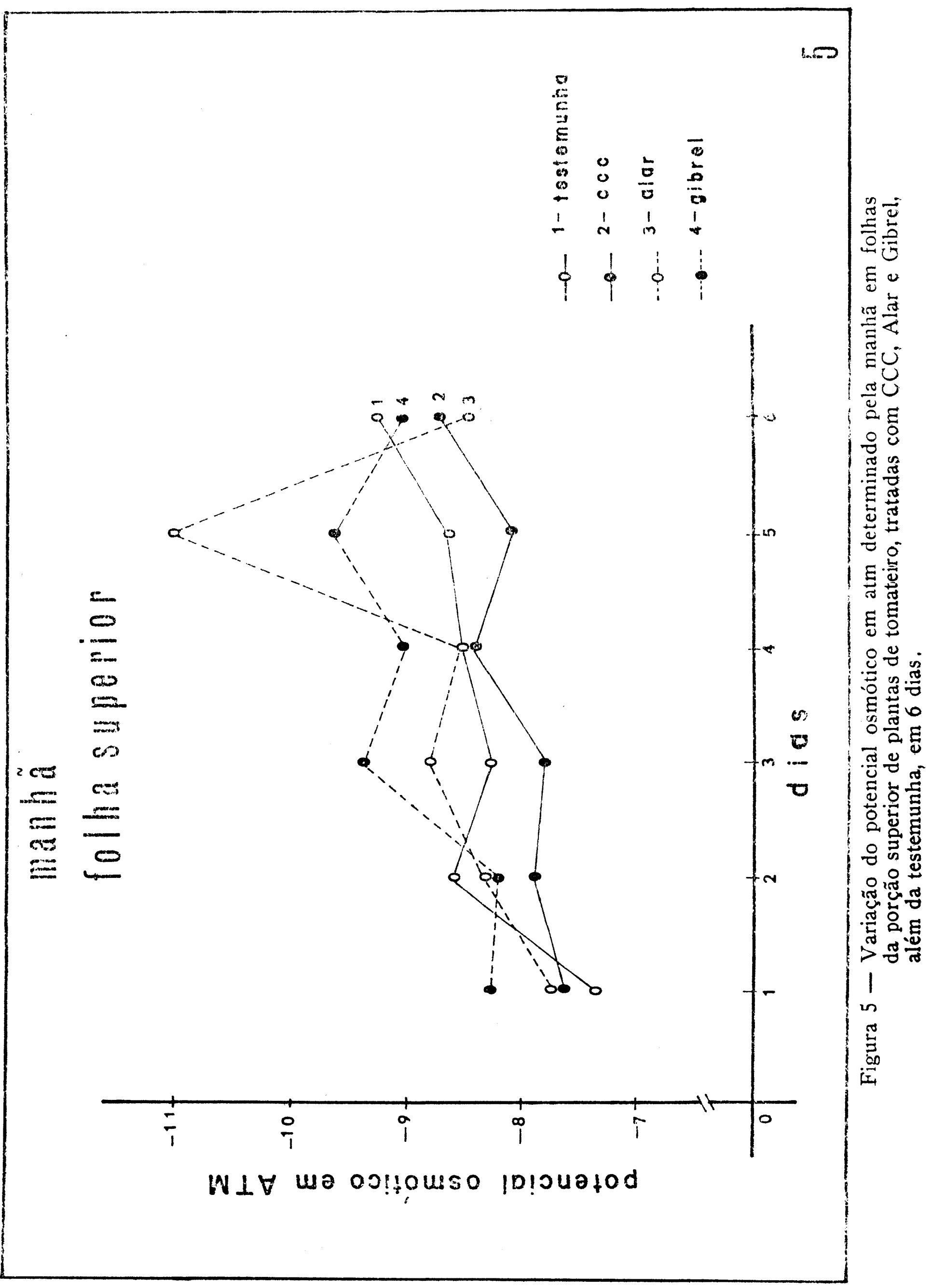




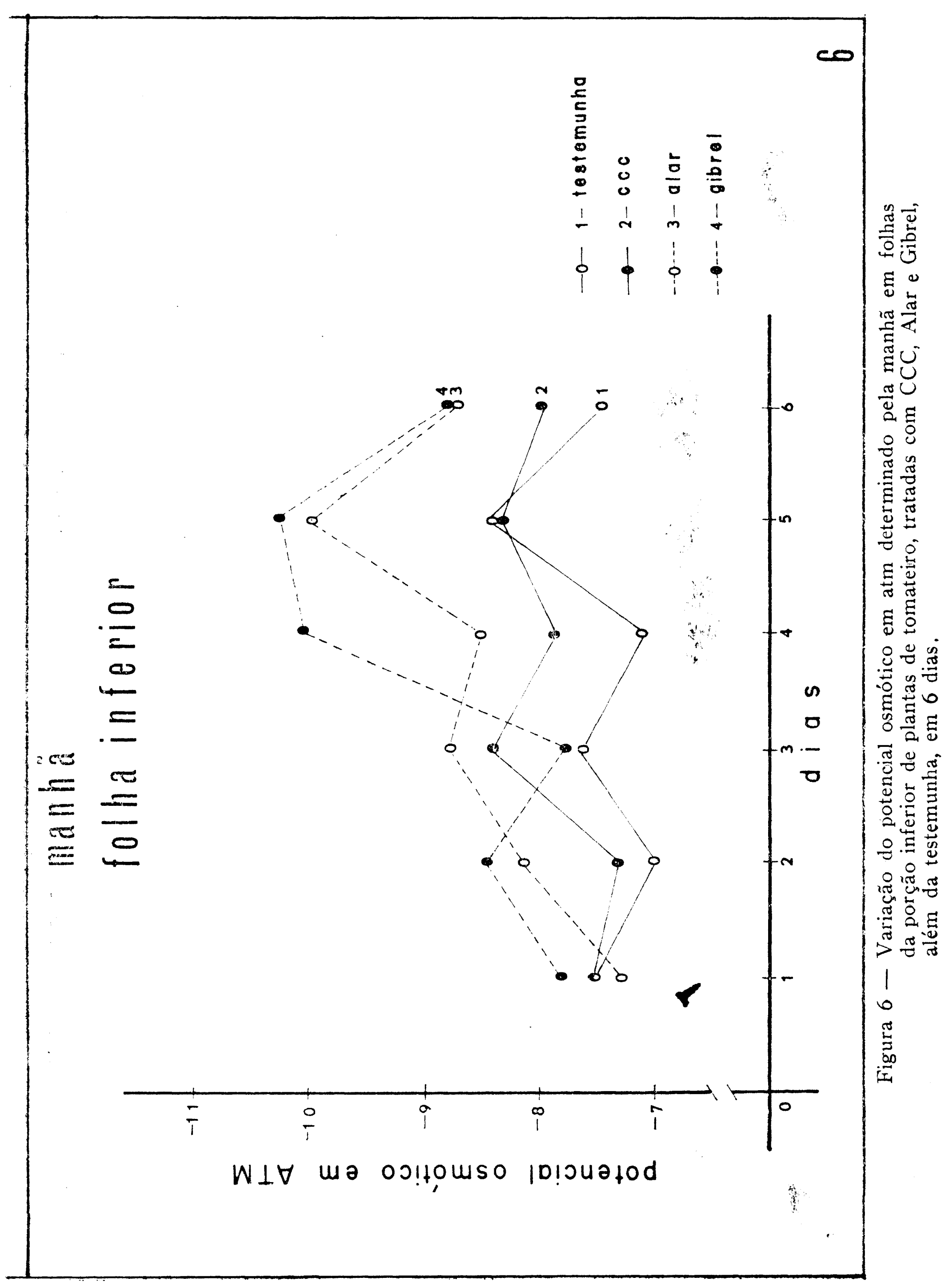




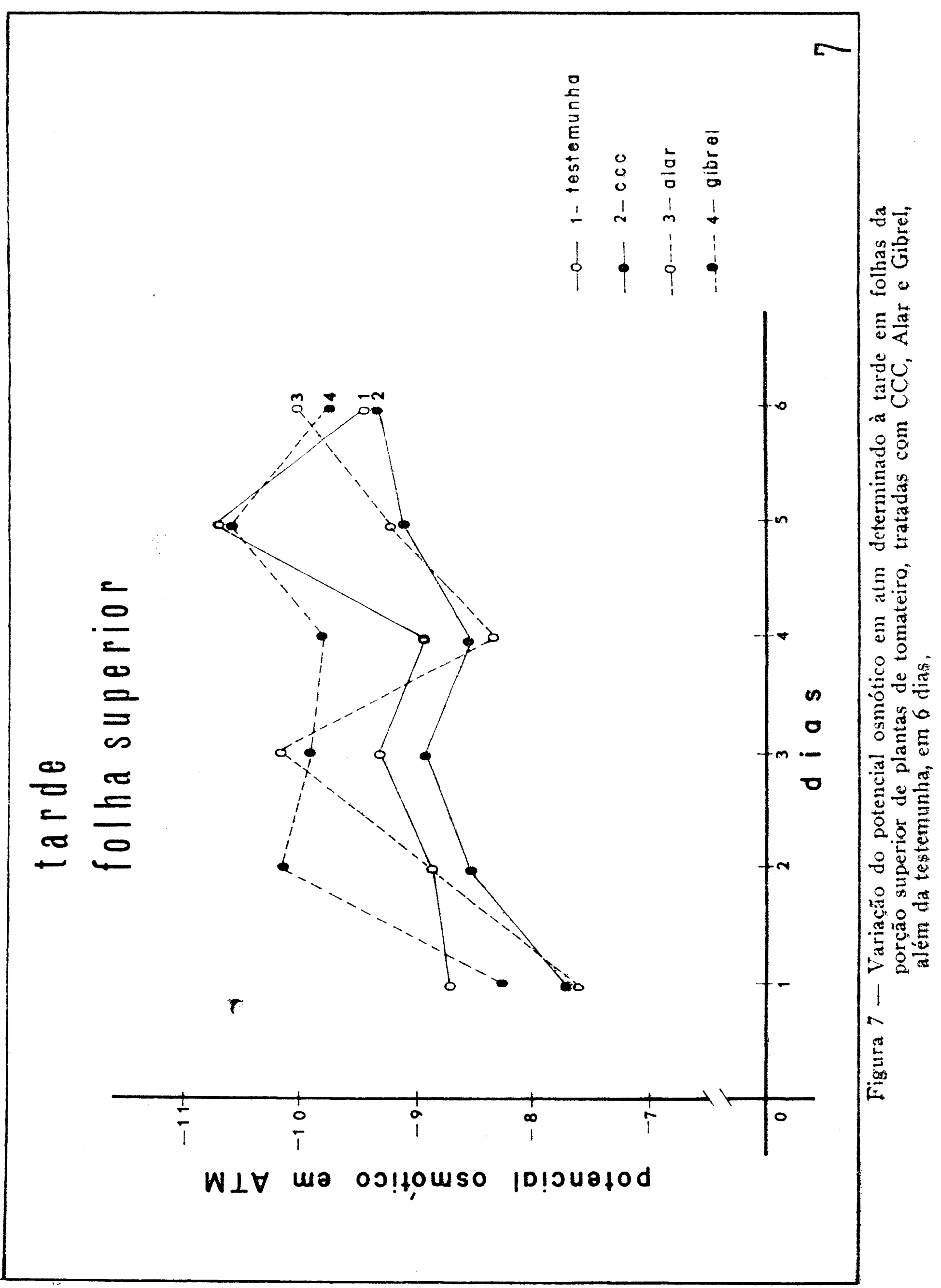




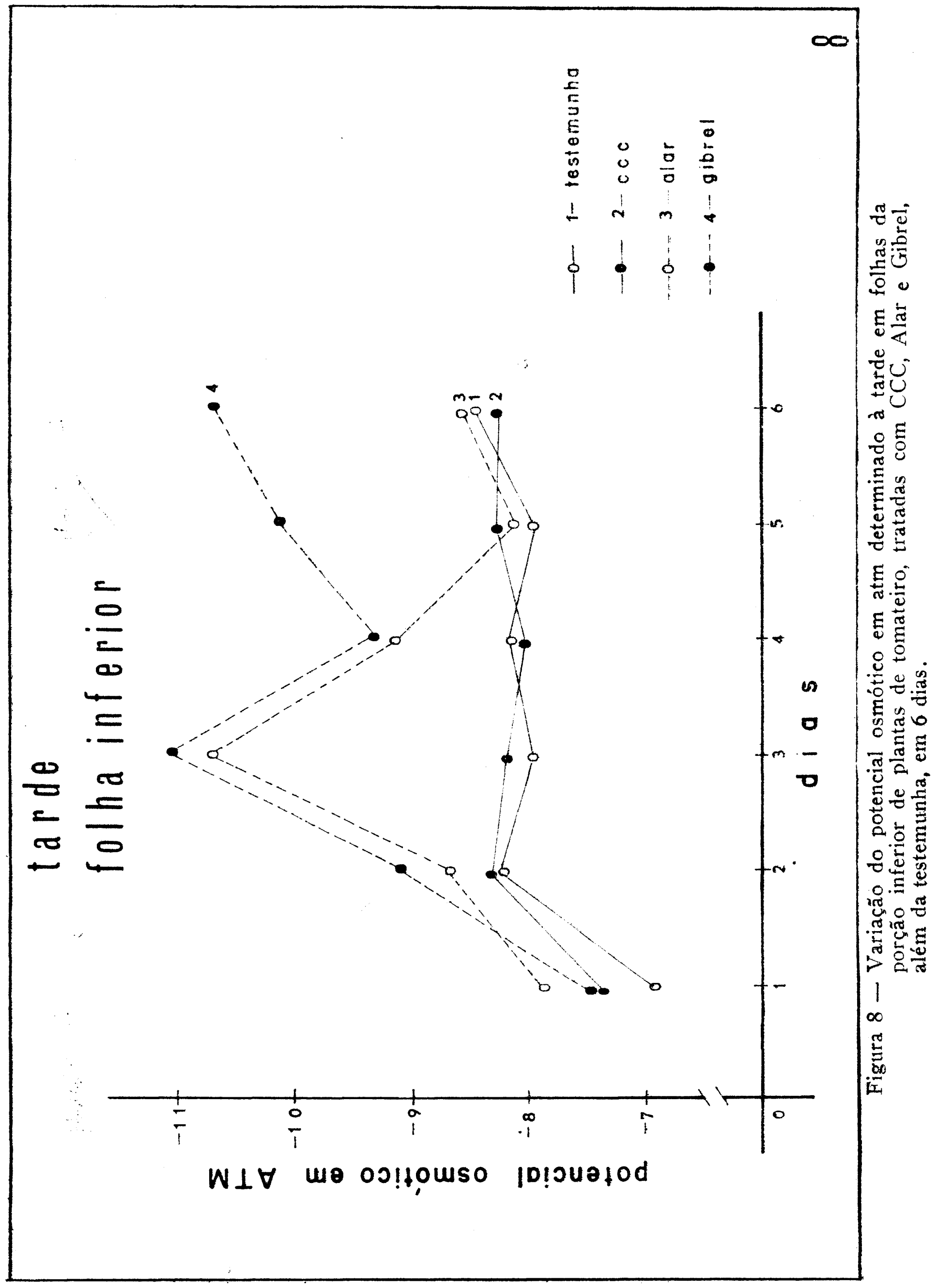


(mais negativo) nas folhas superiores no periodo da tarde. Essas folhas perdem uma elevada quantidade de água nas horas mais quentes do dia, pelo processo transpiratório, apresentando-se assim com menor potencial osmótico. Em seguida verifica-se, na figura, a presença de amostras foliares coletadas pela manhã na parte superior da planta. A região superior da planta mostra-se com valores de potencial osmótico mais baixos em relação às folhas da base do tomateiro. Observa-se então o potencial osmótico das folhas inferiores coletadas no período da tarde; sendo que os potenciais osmóticos mais altos pertencem às folhas inferiores coletadas pela manhã (figura 1). Isto provavelmente se deve à proximidade que as mesmas guardam do substrato do plantio, onde se encontra a fonte de água; sendo que a baixa perda de água e o restabelecimento do equilíbrio hídrico durante à noite, deve estar implicado.

Verifica-se na figura 2 que o CCC restringe as flutuações do potencial osmótico foliar para os limites de $-7,2$ a $-9,3$ atm; sendo que essas flutuações variaram de $-6,9$ a $-10,8$ atm na testemunha. Observa-se novamente um potencial osmótico mais baixo nas folhas superiores coletadas à tarde. Não se nota diferenças acentuadas entre os valores das folhas superiores pela manhã e folhas inferiores coletadas pela manhã e à tarde.

O tratamento com Alar promoveu flutuações pronunciadas no potencial osmótico, principalmente entre as folhas coletadas pela manhã e à tarde (figura 3). Nota-se que as folhas coletadas pela manhã apresentam pequena redução do potencial osmótico até o $44^{\circ}$ dia, sendo que no 5. tencial. As folhas retiradas à tarde reduzem pronunciadamente o potencial osmótico até o $3 .^{\circ}$ dia, sendo que no $4 .^{\circ}$ dia mostraram aumento relativo neste parâmetro.

Observa-se na figura 4 que o tratamento com Gibrel também parece promover variações entre as folhas coletadas pela manhã e aquelas retiradas à tarde. Pode-se notar que no $3 .^{\circ}$ dia, quando as folhas inferiores apresentavam pela manhã um potencial osmótico de - 7,7 atm, mostravam à tarde potencial de - 11,0 atm.

Quando se considera o efeito dos 4 tratamentos nas folhas superiores coletadas pela manhã, verifica-se que tomateiros tratados com CCC mostram potencial osmótico foliar mais alto com relação aos demais. Aplicação de Gibrel parece promover uma redução no potencial osmótico dessas plantas (figura 5) .

Aplicação dos reguladores de crescimento parece afetar diferentemente as folhas inferiores coletadas pela manhã. Observa-se neste caso maior potencial osmótico foliar na testemunha sendo seguida pelo tratamento com CCC. Aplicação de Gibrel e Alar promovem redução no potencial osmótico do tomateiro (figura 6) . 
Quando se observa o efeito dos tratamentos nas folhas superiores coletadas à tarde, notam-se variações nos valores do potencial osmótico no decorrer dos 6 dias. Observa-se marcante flutuação no potencial foliar dos tomateiros tratados com Alar (figura 7).

$\mathrm{Na}$ figura 8 verifica-se alto potencial osmótico foliar na testemunha e nas plantas tratadas com CCC. Aplicação de Gibrel e Alar promove uma pronunciada redução no potencial dos tomateiros, principalmente nos 3 primeiros dias. No $3 .^{\circ}$ dia observa-se potencial da ordem de $-7,9$ atm no controle e - 11,1 atm nas plantas tratadas com Gibrel. Mostra-se bastante distinto o potencial osmótico das folhas inferiores do tomateiro, coletadas à tarde, sob ação dos tratamentos.

\section{CONCLUSÕES} sões:

Os resultados obtidos neste ensaio, permitem as seguintes conclu-

1. Tratamento com giberelato de potássio promoveu abaixamento do potencial osmótico foliar do tomateiro 'Angela'.

2. Aplicação de ácido succínico-2,2-dimetilhidrazida causa variações no potencial osmótico foliar do tomateiro.

3. O cloreto de (2-cloroetil) trimetilamônio promove maior equilíbrio no potencial osmótico foliar do tomateiro estudado.

4. Folhas de tomateiro apresentam pela manhã um potencial osmótico mais alto com relação ao período da tarde.

\section{SUMMARY}

EFFECTS OF (ROWTH REGULATORS ON OSMOTIC POTENTIAL OF TOMATO (Lycopersicon esculentum cr. Angela)

This research doals with the effects of exogenous growth regulators on leaf osmotic potential of tomato cultivar "Angela". To study the influence of growth substances on osmotic potentia, (2-chloroethyl) trimethylammonium chloride (CCC) at concentration of $2.000 \mathrm{ppm}$, succinic acid-2,2-dimethylhydrazide (Alar) $(3,000 \mathrm{ppm})$, and potassium gibberellate (Gibrel) $(100 \mathrm{ppm})$ were applied. The leaf osmotic potential established everyday during six days showed that plants treated with Gibrel presented lower (negative) osmotic potential. CCC promoted better equilibrium in the osmotic potential of tomato plants. Leaves of tomato cultivar "Angela" presented higher osmotic potential in the morning in relation to leaves collected in the afternoon.

\section{LITERATURA CITADA.}

ABELE, J.E. 1963. The physical background to freezing point osmometry and its medical - biological applications. Amer. J. Med. Electronics 2: 32-41.

CASTRO, P.R.C.; JORGE, A.P. 1974. Efeito do cloreto de 2-cloroetil trimetilamônio na transpiração do feijoeiro (Phaseolus vulgaris L.). Supl. Ciência e Cultura $26: 545$. 
CINCOVIC, T. 1966. Results of studies on the water relations of apple leaves relative to their position in the crown. Zborn. Rod. Polp. Tox. Breagad. 14: 1-6.

COLE, D.F.; DOBRENZ, A.K.; MASSENGALE, M.A. 1971. Effect of growth regulator and antitranspirant chemicals on water requirement and growth components of alfalfa (Medicago sativa L). Crop Science 11:582-584.

FILIPOV, L.A. 1964. The formation of drought resistance properties of apple leaves during growth under the influence of external conditions. Fisiologiya Rastenii 11: 529-531.

KULL, U. 1971. Effect of CCC on strange behaviour of vegetative plant parts. Ber. Dent. Ges. 84: 299-308.

LEE, K.C.; CAMPBELL, R.W.; PAULSEN, G.M. 1974. Effects of drought stress and succinic acid-2,2-dimethylhydrazide treatment on water relations and photosynthesis in pea seedlings. Crop Science 14: 279-282.

MISHRA, D.; PRADHAN, G.C. 1972. Effect of transpiration-reducing chemicals on growth, flowering and stomatal opening of tomato plants. Plant Physiol. 50: $271-274$.

SINGH, K.; YOUNG, J.O. 1971. Effect of 2-chloroethyl trimethylammonium chloride on growth behaviour and transpiration related to tomato fruit cracking. J. Nkvv. Res. J. 5: 22-27.

SOLOMONOVSKII, L.Y. 1972. Effect of CCC on indexes of the water system and cold hardiness of tomatoes. Isv. Sib. Otor. Akad. Nank. 1:57-60.

TAL, M.; IMBER, D. 1971. Abnormal stomatal behaviour and hormonal imbalance in Flacca, a wilty mutant of tomato. II. Hormonal effects on the water status in the plant. Plant Physiol. 47:849-850.

WALTER, H.; VAN STADEN, J. 1965. Uberdic Jahreskurven des osmotischen Werts bei insigen Hortlanbarten des Kaplandes. J.S. Afs. Bot. 31:225-236. 